\title{
Rat Hippocampal Neurons Are Critically Involved in Physiological Improvement of Memory Processes Induced by Cholecystokinin-B Receptor Stimulation
}

\author{
Angélique Sebret, ${ }^{1}$ Isabelle Léna, ${ }^{1}$ Dominique Crété, ${ }^{1}$ Toshimitsu Matsui,, ${ }^{2}$ Bernard P. Roques, ${ }^{1}$ \\ and Valérie Daugé 1 \\ ${ }^{1}$ Département de Pharmacochimie Moléculaire et Structurale, Institut National de la Santé et de la Recherche Médicale \\ U266, Centre National de la Recherche Scientifique, Unité Mixte de Recherche 8600, Unité de Formation et de \\ Recherche des Sciences Pharmaceutiques et Biologiques, 75270 Paris Cedex 06, France, and 2Third Division \\ Department of Medicine, Kobe University School of Medicine, Kobe 650-0017 Japan
}

The involvement in memory processes of the neuropeptide cholecystokinin (CCK) through its interaction with the CCK-B receptors was studied. The two-trial recognition memory task was used. Control animals showed recognition memory after a $2 \mathrm{hr}$ time interval but not after a $6 \mathrm{hr}$ time interval between the two trials. The improving effect of a selective CCK-B agonist, BC 264, intraperitoneally administered $(0.3 \mu \mathrm{g} / \mathrm{kg})$ in the retrieval phase of the task (6 hr time interval), was also observed after its injection (1 pmol/0.5 $\mu \mathrm{l})$ in the dorsal subiculum/CA1 of the hippocampus but not in the caudate/putamen nucleus or in the prefrontal cortex of rats. The CCK-B antagonist L-365,260 injected $(10 \mathrm{ng} / 0.5 \mu \mathrm{l})$ into this region of the hippocampus abolished the improving effect of BC 264 injected intraperitoneally. Furthermore, L-365,260 injected in the hippocampus suppressed the recognition of the novel arm normally found in the controls ( $2 \mathrm{hr}$ time interval) when it was injected before the acquisition or the retrieval phase of the task. In addition, an increase of the extracellular levels of CCK-like immunoreactivity in the hippocampus of rats during the acquisition and retention phase of the task was observed. Finally, CCK-B receptordeficient mice have an impairment of performance in the memory task (2 hr time interval).

Together, these results support the physiological involvement of the CCKergic system through its interaction with CCK-B receptors in the hippocampus to improve performance of rodents in the spatial recognition memory test.

Key words: cholecystokinin-B receptors; spatial memory; CA1; prelimbic-infralimbic cortex; CCK release; CCK-B receptor-deficient mice
The sulfated octapeptide cholecystokinin $\left(\mathrm{CCK}_{8}\right)$ exerts its effects through two G-protein-coupled receptors (Wank et al., 1992; Lee et al., 1993): CCK-B receptors are found essentially in the CNS and CCK-A receptors are highly concentrated in the gastrointestinal tract but are also found in particular brain structures (Hill et al., 1987; Mercer and Beart, 1997).

Modulation of memory processes by the CCKergic system has been demonstrated in studies using, in most of them, active and passive avoidance tests (Katsuura and Itoh, 1986; for review, see Itoh and Lal, 1990; Daugé and Léna, 1998). However, the role of each receptor type and the physiological involvement of the CCKergic system in memory processes remain poorly understood. We have shown recently that systemic administration of selective CCK-B agonists, such as BC 264 (Charpentier et al., 1988), pBC 264 (Corringer et al., 1992), or RB400 (Million et al., 1997), improved the cognitive performances of rats measured in the spontaneous alternation test and a spatial two-trial memory task (Ladurelle et al., 1997; Million et al., 1997; Léna et al., 1999;

\footnotetext{
Received March 23, 1999; revised May 17, 1999; accepted May 20, 1999.

We thank H. Dhôtel for the synthesis of BC 264 and M. Beinfeld for a critical reading of this manuscript.

Correspondence should be addressed to Dr. Valérie Daugé, Département de Pharmacochimie Moléculaire et Structurale, Institut National de la Santé et de la Recherche Médicale U266, Centre National de la Recherche Scientifique, Unité Mixte de Recherche 8600, Unité de Formation et de Recherche des Sciences Pharmaceutiques et Biologiques, 4, avenue de l'Observatoire, 75270 Paris Cedex 06, France.

Copyright (C) 1999 Society for Neuroscience $\quad 0270-6474 / 99 / 197230-08 \$ 05.00 / 0$
}

Taghzouti et al., 1999). These effects were dependent on the dopaminergic (DAergic) system in the anterior part of the nucleus accumbens (N.Acc.) (Ladurelle et al., 1997).

However, the systemic effects of BC 264 could not result from a direct interaction between CCK-B receptors and DAergic terminals in the N.Acc., because opposite behavioral and biochemical responses were observed when this compound was locally injected in the anterior N.Acc. (Daugé et al., 1992; Ladurelle et al., 1993). This means that stimulation of CCK-B receptors localized in cerebral structures other than the N.Acc. could be responsible of the effects occurring at this level. The neurons of the N.Acc. receive an intense DAergic innervation from the ventral tegmental area and glutamatergic projections from the hippocampus, the prefrontal cortex, and the amygdala (Groenewegen et al., 1991). Interestingly, anatomical data showed that CCKergic terminals establish direct synaptic contact with glutamatergic neurons of the hippocampus that project to the N.Acc. (Totterdell and Smith, 1986), and BC 264 was shown to increase the glutamate and aspartate release and the firing rate of the CA1 neurons of the hippocampus of rats (Daugé et al., 1990; Migaud et al., 1994).

The present study was therefore designed to define the role of brain structures, in particular the hippocampus and the prefrontal cortex, in the effects of BC 264 in a two-trial memory task in rats. This was achieved by local injection of BC 264 or the selective CCK-B antagonist L-365,260 (Chang and Lotti, 1986) in these structures. Furthermore, the physiological involvement of the CCKergic system in a spatial memory task was investigated using 
local injection of L-365,260 in the hippocampus of rats, by behavioral analysis of mice with a deletion of CCK-B receptors (Nagata et al., 1996) and by quantification of the extracellular levels of CCK-like immunoreactivity (CCK-LIR) in the hippocampus by microdialysis in rat submitted or not to the memory task.

\section{MATERIALS AND METHODS}

\section{Subjects}

Male Wistar rats (Charles River, Saint-Aubin les Elbeuf, France) weighing $180-200 \mathrm{gm}$ at the time of surgery were used. They were housed in groups of four in a temperature-controlled $\left(22 \pm 1^{\circ} \mathrm{C}\right)$ and humiditycontrolled $(50 \pm 5 \%)$ environment and had access to food and water $a d$ libitum. Each animal was handled daily for $3 \mathrm{~d}$ before the experiments.

CCK-B/gastrin receptor-deficient mice were provided from the original background 129sv/C57BL6 mice (Nagata et al., 1996). Breeding and genotype analysis have been done by Transgenic Alliance (L'Arbresle, France). Twenty-five CCK-B receptor-deficient mice (13 males and 12 females) and 26 mice (13 males and 13 females) of 129sv/C57BL6 genetic background ( 3 months old) were used. They were housed at least 1 week before the experiments in the laboratory in a temperature-controlled $\left(22 \pm 1^{\circ} \mathrm{C}\right)$ and humidity-controlled $(50 \pm 5 \%)$ environment and had access to food and water ad libitum.

The animals were treated as approved by the local committee and in accordance with the NIH Guidelines for the Care and Use of Laboratory Animals (1985).

\section{Surgery}

Rats were anesthetized by an intraperitoneal injection of chloral hydrate $(400 \mathrm{mg} / \mathrm{kg}$ ), mounted in a stereotaxic apparatus (Unimécanique), and implanted bilaterally with 25 -gauge stainless steel cannula guides (0.6 $\mathrm{mm}$ in external diameter) for local injection experiments. Unilateral stainless steel cannula guides of 20 -gauge were used for microdialysis experiments. In both cases, cannulas were positioned $1.5 \mathrm{~mm}$ above the structures. The coordinates, taken from the atlas of Paxinos and Watson (1986) were as follows: (1) $+1.6 \mathrm{~mm}$ anterior to the interaural; $\pm 3.8 \mathrm{~mm}$ lateral to the midline; and $-1.8 \mathrm{~mm}$ under the skull surface for the dorsal subiculum/CA1 of the hippocampus; (2) $+0.1 \mathrm{~mm}$ anterior from bregma; $\pm 2.7 \mathrm{~mm}$ lateral to the midline; and $-4 \mathrm{~mm}$ under the skull surface for the caudate/putamen nucleus; (3) $+3 \mathrm{~mm}$ anterior from bregma; \pm 0.6 $\mathrm{mm}$ lateral to the midline; and $-3.7 \mathrm{~mm}$ under the skull surface for the prelimbic/infralimbic cortex. Cannulas were secured to the skull with stainless steel screws and dental cement. Animals were used for experiments after a recovery period of $7 \mathrm{~d}$.

\section{Microinfusion procedure}

Drugs and control solutions were injected bilaterally through the cannula guide. A volume of $0.5 \mu \mathrm{l} /$ side over 2 min was administered using a Precinorm pump through 30.5-gauge stainless steel needles attached to a $10 \mu \mathrm{l}$ microsyringe (Hamilton) by polyethylene tubing. The stainless steel needles were $1.5 \mathrm{~mm}$ longer than the cannula guide and were left in situ for $30 \mathrm{sec}$ to allow diffusion of the drug.

\section{Behavioral experiments}

The memory task used (two-trial memory task in mice and rats), based on the exploration of novelty, was first described by Dellu et al. (1992, 1997). Experiments with rats were performed in a wooden Y maze (40 $\mathrm{cm}$ long, $15 \mathrm{~cm}$ wide, and $35 \mathrm{~cm}$ high) covered with black vinyl and illuminated by a 30 lux light. The floor of the maze was covered with sawdust, which was mixed after each animal was tested. The behavior of the animals was observed with a video camera connected to a computer outside the testing sound-attenuated room. Numerous visual cues were placed on the walls and were kept constant during the experiments. Experiments with mice were performed as described above with rats, except the dimensions of the wooden $\mathrm{Y}$ maze were different $(25 \mathrm{~cm}$ long, $8 \mathrm{~cm}$ wide, and $15 \mathrm{~cm}$ high).

The test consisted of two trials, separated by different time intervals. During the first trial (acquisition phase), one arm of the $\mathrm{Y}$ maze was closed, and the animals explored the other two arms. During the second trial (retrieval phase), the rats had access to the three arms. The time spent in each arm of the maze and the total number of arm visits were measured. The results are expressed as percentage of time spent in the novel arm. The animals were placed in the same arm of the maze at the beginning of each trial, but the position of the closed arm was alternated to the left or to the right of this arm, respectively, for half of the animals of each group tested.

In some local injection experiments with rats, the first and second trials, which lasted 3 and $2 \mathrm{~min}$, respectively, were separated by a $6 \mathrm{hr}$ time interval for which the control rats did not recognize the novel arm and explored the three arms equally $(33.3 \%$ of visit duration in each arm). The time interval of $6 \mathrm{hr}$ allowed the memory-improving effect of the drug to be studied, assessed by an increase in the exploration of the novel arm.

In the other experiments, the trials were separated by a $2 \mathrm{hr}$ time interval for which the control rats spent more time exploring the novel arm. This time interval allowed the memory-impairment effect of the drug to be studied.

For microdialysis experiments, the two trials lasted $30 \mathrm{~min}$ because the samples were collected every $30 \mathrm{~min}$. During the intertrial interval, rats were put back in the microdialysis box. The trials were separated by a 2 hr time interval. This time interval allowed changes in levels of CCKLIR to be linked to the cognitive process.

For mutant and wild-type mice, the task is the same as the previously described one for the rats. The first and second trials, which lasted 3 and $2 \mathrm{~min}$, respectively, were separated by a $2 \mathrm{hr}$ time interval for which control mice recognized and spent more time in the novel arm.

\section{Experimental procedure for local injections in the two-trial memory task in rats}

Dorsal subiculum/CA1 of the hippocampus. In the dorsal subiculum/CA1 of the hippocampus, four series of experiments were done.

The first consisted of a local injection of the CCK-B antagonist L-365,260 $15 \mathrm{~min}$ after the intraperitoneal injection of the CCK-B agonist BC 264. The agonist was administered $30 \mathrm{~min}$ before the second trial (i.e., the retrieval phase) after a $6 \mathrm{hr}$ intertrial interval. The following groups were studied: (1) control, $0.5 \%$ cyclodextrin locally plus saline intraperitoneally $(n=12)$; (2) CCK-B antagonist group, $10 \mathrm{ng} / 0.5 \mu \mathrm{l}$ L-365,260 plus saline intraperitoneally $(n=13)$; (3) CCK-B agonist group, $0.5 \%$ cyclodextrin locally plus $0.3 \mu \mathrm{g} / \mathrm{kg} \mathrm{BC} 264$, i.p. $(n=12)$; and (4) CCK-B agonist and antagonist group, $10 \mathrm{ng} / 0.5 \mu \mathrm{l}$ L-354,260 plus 0.3 $\mu \mathrm{g} / \mathrm{kg} \mathrm{BC} 264(n=13)$.

The second series of experiment corresponding to local injection of BC 264 in the dorsal subiculum/CA1 of the hippocampus required three experiments. Local injections of BC 264 were made 15 min before the second trial of the memory task after a $6 \mathrm{hr}$ intertrial interval. In the first, two doses were tested: $10 \mathrm{fmol}(n=6)$ and 1 pmol $(n=4)$ (control group, $n=5)$. In the second experiment, BC 264 was tested at two doses: 100 fmol $(n=9)$ and 1 pmol $(n=6)$ (control group, $n=5)$. In the third experiment, two doses were tested: $500 \mathrm{fmol}(n=9)$ and 1 pmol $(n=5)$ (control group, $n=8$ ). Results were pooled because there was no statistical difference between control groups and between the same doses in the three experiments.

The third series consisted of performing local injection of L-365,260 in the dorsal subiculum/CA1 of the hippocampus $15 \mathrm{~min}$ before the first trial of the two-trial memory task ( 2 hr intertrial interval): control, $0.5 \%$ cyclodextrin $(n=8) ; 10 \mathrm{ng} / 0.5 \mu \mathrm{l} \mathrm{L-365,260}(n=9)$.

The fourth series consisted of performing local injection of L-365,260 in the dorsal subiculum/CA1 of the hippocampus $15 \mathrm{~min}$ before the second trial of the two-trial memory task after a $2 \mathrm{hr}$ intertrial interval: control, $0.5 \%$ cyclodextrin $(n=9) ; 10 \mathrm{ng} / 0.5 \mu \mathrm{L}-365,260(n=10)$.

Caudate/putamen nucleus. In the caudate/putamen nucleus, BC 264 was tested at one dose: $1 \mathrm{pmol}, n=11$; control group, $n=12$. It was injected $15 \mathrm{~min}$ before the second trial of the two-trial memory task after a $6 \mathrm{hr}$ inter-trial interval.

Prefrontal cortex. In the prefrontal cortex, BC 264 was tested at four doses: $100 \mathrm{fmol}(n=9), 1 \mathrm{pmol}(n=9), 10 \mathrm{pmol}(n=8)$, or $100 \mathrm{pmol}$ $(n=8)$ (control group, $n=10)$. BC 264 was injected 15 min before the second trial of the two-trial memory task after a $6 \mathrm{hr}$ intertrial interval.

\section{Brain dialysis procedure}

The dialysis probes, constructed according to the method of Robinson and Whishaw (1988), consisted of a $2.5 \mathrm{~mm}$ long semipermeable polyacrilonitrile AN69 membrane with a molecular size cutoff of 40,000 Da and an external diameter of $0.3 \mathrm{~mm}$ (a generous gift from HOSPAL, Lyon, France), connected to a perfusion system as described previously by Daugé et al. (1996). 
The probes were inserted into chronically implanted cannula guides and positioned so that active membrane crossed the structure studied and were maintained in position by a locking screw. This was performed 14-15 hr before the experiments, and the rats were put into individual black boxes $(40 \times 40 \times 40 \mathrm{~cm})$ with access to food and water ad libitum to habituate the animals to the new environment and to the connection system of dialysis. After the $14-15 \mathrm{hr}$ postimplantation period, the microdialysis probes were connected to a microsyringe pump (Precinorm) via a channel liquid swivel. The perfusion was achieved at the flow rate of $2 \mu \mathrm{l} / \mathrm{min}$ with a dialysis buffer $(120 \mathrm{~mm} \mathrm{NaCl}, 5 \mathrm{mM} \mathrm{KCl}, 1.8 \mathrm{~mm}$ $\mathrm{CaCl}_{2}, 1.2 \mathrm{mM} \mathrm{MgCl}_{2}, 0.01 \% \mathrm{BSA}$, and $0.2 \mathrm{~mm}$ PBS, pH 7.4).

After $2 \mathrm{hr}$ of perfusion, samples were collected every $30 \mathrm{~min}$ in tubes maintained in dry ice. The samples were maintained at $-80^{\circ} \mathrm{C}$ until the quantification of CCK-like material. Two experiments were made. The first consisted of collecting the samples of control rats left for $4 \mathrm{hr} 30 \mathrm{~min}$ in their box. The second was to collect the samples of rats submitted to the two-trial task after a $2 \mathrm{hr}$ time interval, as described above, except that the duration of the two trials was $30 \mathrm{~min}$ to be in synchronization with the dialysis sample collection $(30 \mathrm{~min})$. The first four samples of microdialysis were used to calculate the basal efflux of CCK-LIR before the two-trial memory task.

\section{Radioimmunoassay dosage of CCK-LIR}

The quantification of CCK-LIR in the dialysates was performed as described previously by Daugé et al. (1999). The C-terminal antibody 8007 (a generous gift from Professor J. Rehfeld, Copenhagen, Denmark) $\left(1: 7.5 \times 10^{-5}\right)$ was incubated at $4^{\circ} \mathrm{C}$ for $4 \mathrm{~d}$ with $\mathrm{CCK}_{8}$ standards or with dialysis samples and ${ }^{125} \mathrm{I} \mathrm{CCK}_{8}$ in the RIA buffer $(20 \mathrm{~mm}$ barbital buffer, $0.6 \mathrm{~mm}$ thiomersal, and $0.11 \% \mathrm{BSA} \mathrm{v} / \mathrm{v}$; the final $\mathrm{pH}$ was adjusted to 8.4 ). Bound and free fractions were separated by adsorbing the free ${ }^{125} \mathrm{I} \mathrm{CCK}_{8}$ onto active dextran T70-coated charcoal, $4 \mathrm{gm} / 1$ and $40 \mathrm{gm} / 1$, respectively, in the RIA buffer containing $10 \%$ filtered horse serum. Radioactivity in the bound fraction was measured by a gamma counter (Kontron Elektronik, Eching, Germany). Under these conditions, 0.5 pg of CCKLIR can be detected in the dialysates. The percentages of cross reactivity of CCK antibodies were $50.5 \%$ for $\mathrm{CCK}_{8} \mathrm{NS}, \mathrm{CCK}_{7} \mathrm{~S}$, and $\mathrm{CCK}_{7} \mathrm{NS}$ and $0.001 \%$ for $\mathrm{CCK}_{5}$ and $\mathrm{CCK}_{4}$.

\section{Drugs}

L-365,260 (3R-(+)- $N$-(2,3-dihydro-1methyl-2-oxo-5-phenyl-1H-1,4-benzodiazepin-3yl)- $N^{\prime}$-(3-methyl phenyl) urea) (Chang and Lotti, 1986), a generous gift of Rhône-Poulenc Rorer (Antony, France), was dissolved in cyclodextrin $(0.5 \%)$. BC 264 (Boc- $\mathrm{Tyr}\left(\mathrm{SO}_{3} \mathrm{H}\right)$-gNle-mGly-Trp(NMe)Nle-Asp-Phe- $\mathrm{NH}_{2}$ ) (Charpentier et al., 1988), synthesized in the laboratory, was dissolved in $\mathrm{NaCl}(0.9 \%) .{ }^{125} \mathrm{I} \mathrm{CCK}_{8}$ was provided by Amersham (Les Ulis, France).

\section{Histological control}

Rats were killed with an overdose of chloral hydrate. The brains were removed and frozen in isopentane solution at $-40^{\circ} \mathrm{C}$, and $30 \mu \mathrm{m}$ slices were cut with a microtome. The position of the cannula or the probes was estimated according to the atlas of Paxinos and Watson (1986). Figure 1 shows a schematic representation of the injection needle locations $(A$, the prelimbic/infralimbic cortex; $B$, the caudate/putamen nucleus; $C$, the dorsal subiculum/CA1 of the hippocampus). For microdialysis experiments, only the data of rats having probes that traversed $70 \%$ of the dorsal subiculum/CA1 of the hippocampus were retained for calculations.

\section{Statistical analysis}

For microdialysis experiment, data were analyzed by one-way ANOVA, followed by a pairwise comparison with Dunnett's test.

For behavioral studies with mice and rats, a one-way ANOVA, followed by Dunnett's test or Duncan test, was used.

The dose-effect curves of BC 264 obtained after local injection in the dorsal subiculum/CA1 of the hippocampus required three experiments, but data were pooled because no significant difference was obtained between the values of control animals and between the same doses in the different experiments.

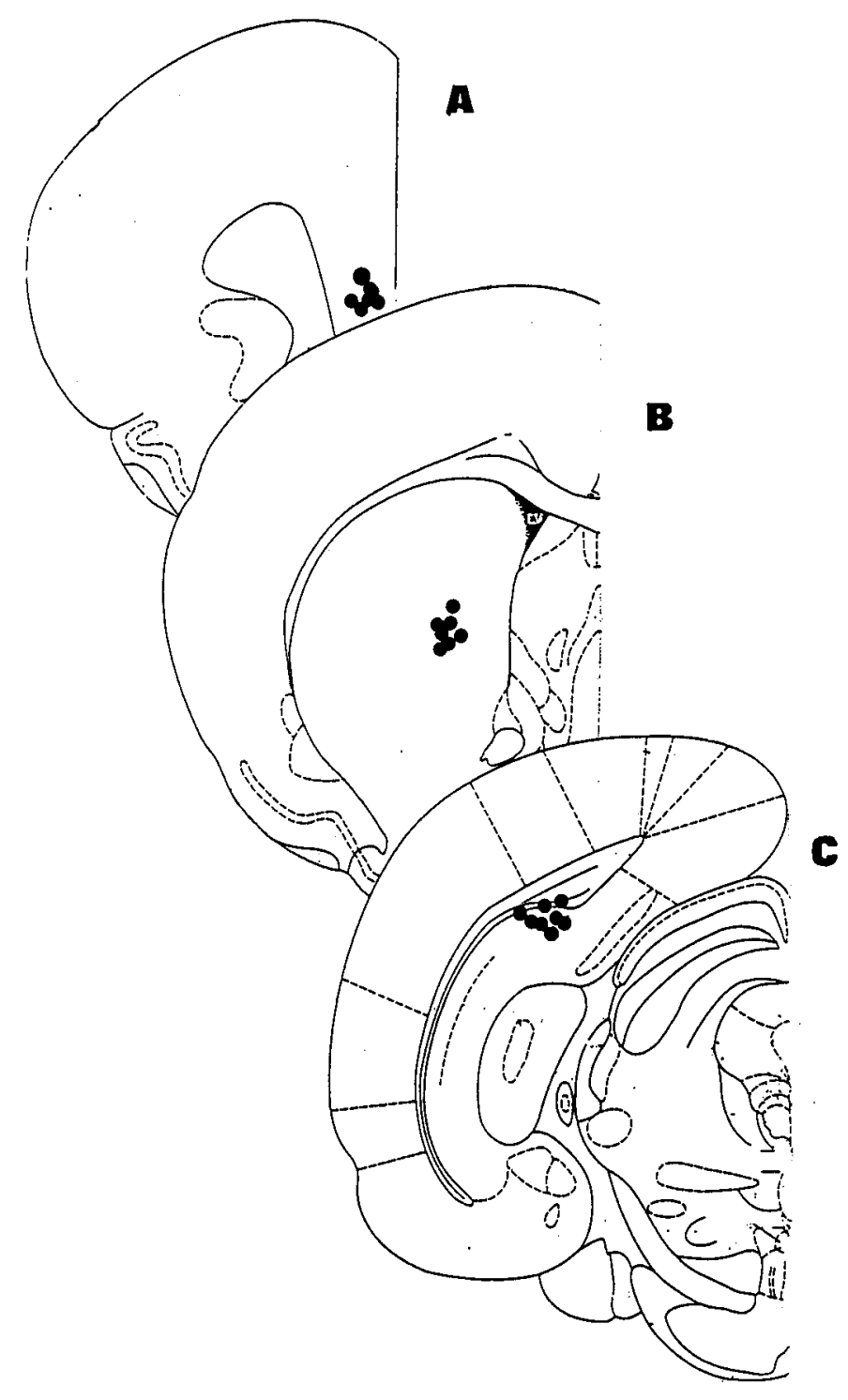

Figure 1. Schematic representation of the injection needles located in the prelimbic/infralimbic cortex $(A)$, the caudate/putamen nucleus $(B)$, and the dorsal subiculum/CA1 of the hippocampus $(C)$.

\section{RESULTS}

\section{Behavioral effects of CCK agonist and antagonist compounds locally injected in the dorsal subiculum/ CA1 of the hippocampus in rats}

Effects of BC 264 with and without L-365,260 in the two-trial memory task after a $6 \mathrm{hr}$ intertrial interval

BC 264, intraperitoneally administered in rat at the dose of 0.3 $\mu \mathrm{g} / \mathrm{kg} 30 \mathrm{~min}$ before the second trial (retrieval phase) of the two-trial memory test, increased the time spent in the novel arm, improving performance of rats as expected from previous experiments (Léna et al., 1999). Local injection in the dorsal subiculum/CA1 of the hippocampus of the CCK-B antagonist $\mathrm{L}-365,260$ at the dose of $10 \mathrm{ng} / 0.5 \mu \mathrm{l}$ did not modify the time spent in the novel arm. However, its administration 15 min after the injection of BC 264 significantly suppressed the enhancement of the time spent in the novel arm produced $30 \mathrm{~min}$ after the intraperitoneal injection of $0.3 \mu \mathrm{g} / \mathrm{kg}$ of BC $264\left(F_{(3,46)}=2.94\right.$; $p=0.04$ ) (Fig. 2), showing that the effect of BC 264, intraperi- 


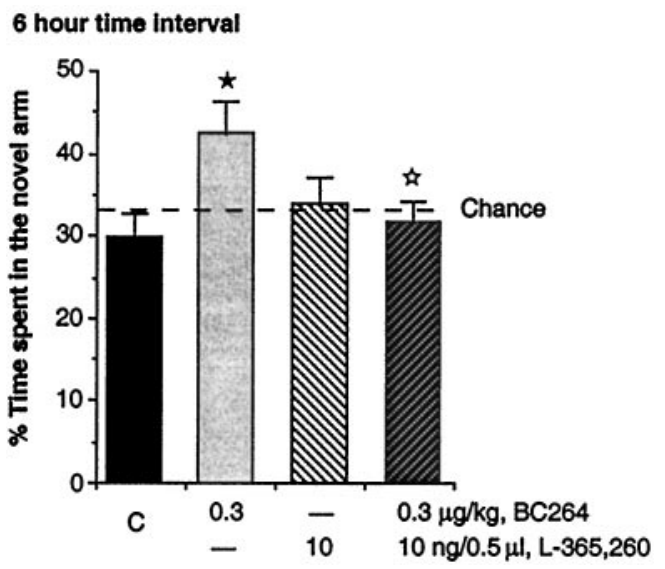

Figure 2. Effect of the CCK-B antagonist L-365,260 (10 ng/0.5 $\mu \mathrm{l})$ locally injected into the dorsal subiculum/CA1 of the hippocampus on the improvement of the performance of rats in the two-trial memory test produced by the intraperitoneal injection of the CCK-B agonist BC 264 $(0.3 \mu \mathrm{g} / \mathrm{kg})$. L-365,260 was injected 15 min after BC 264. BC 264 was injected $30 \mathrm{~min}$ before the second trial (retrieval phase) of the task after a $6 \mathrm{hr}$ time interval. L-365,260 was dissolved in cyclodextrin $(0.5 \%)$, and BC 264 was dissolved in saline. $C$, Control; rats received $0.5 \mu \mathrm{l} /$ side of cyclodextrin $(0.5 \%)$ in the dorsal subiculum/CA1 of the hippocampus plus $1 \mathrm{ml} / \mathrm{kg}$ saline intraperitoneally. Results are expressed as mean \pm SEM of the percentage of time spent in the novel arm. $\star p<0.05$ versus control group; $s p<0.05$ versus BC 264 group; Duncan test.

toneally injected, was dependent on the CCK-B receptor stimulation in the hippocampus. Both compounds were injected before the second trial of the task (retrieval phase). L-365,260 and BC 264 did not change the total number of visits in the three arms of the maze (data not shown).

\section{Effects of BC 264 in the two-trial memory task after a $6 \mathrm{hr}$ intertrial interval}

Figure $3 A$ shows that, 15 min after local injection in the dorsal subiculum/CA1 of the hippocampus of 1 pmol of BC 264, rats spent significantly more time in the novel arm during the second trial compared with the control group $\left(F_{(4,52)}=3.148 ; p=0.01\right)$. This indicates that BC 264 improved performance of rats. The other doses $(0.01,0.1$, and $0.5 \mathrm{pmol})$ tested did not significantly modify the time spent in the novel arm compared with the control group. BC 264 did not change the total number of arms visits (data not shown).

Effects of local injection of L-365,260 in the two-trial memory task after a $2 \mathrm{hr}$ intertrial interval

In Figure $4 A$, control rats spent more time in the novel arm than in the others after a $2 \mathrm{hr}$ intertrial interval. The injection of L-365,260 at the dose of $10 \mathrm{ng} / 0.5 \mu \mathrm{l}$ in the dorsal subiculum/CA1 of the hippocampus $15 \mathrm{~min}$ before the first trial of the two-trial memory task (acquisition phase) induced a decrease in the time spent in the novel arm compared with the control group $\left(F_{(1,15)}=\right.$ $17.453 ; p=0.0008$ ) (Fig. $4 A$ ). The total number of arm visits were not changed compared with the control group (data not shown).

The injection of L-365,260 at the dose of $10 \mathrm{ng} / 0.5 \mu \mathrm{l} 15 \mathrm{~min}$ before the second trial (retrieval phase) significantly decreased the time spent in the novel arm compared with the control group $\left(F_{(1,17)}=5.825 ; p=0.02\right)$ (Fig. $\left.4 B\right)$. The total number of visits were not changed compared with the control group (data not shown).

The rats treated with $\mathrm{L}-365,260$ did not recognize the novel
A Dorsal subiculum/CA1
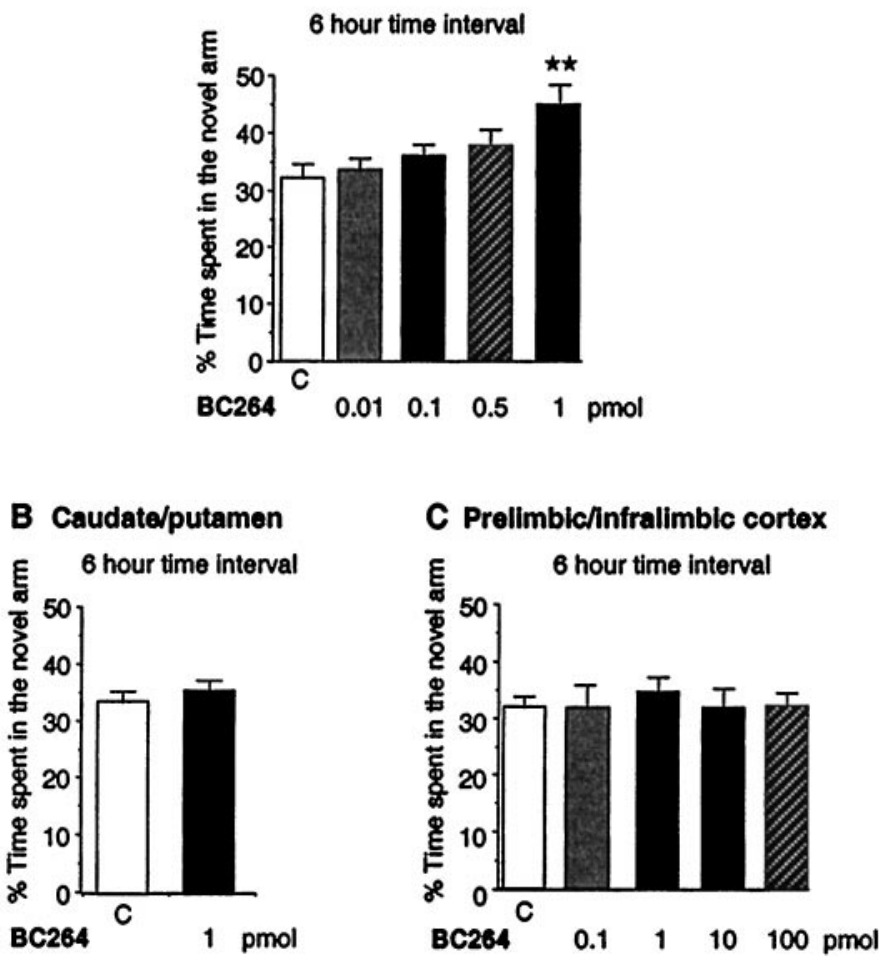

Figure 3. Effects of BC 264 locally injected in the dorsal subiculum/CA1 of the hippocampus $(A)$, the caudate/putamen nucleus $(B)$, and the prelimbic/infralimbic cortex $(C)$ in the two-trial memory task after a $6 \mathrm{hr}$ time interval. BC 264 was injected 15 min before the second trial (retrieval phase) of the test. Control group $(C)$ was locally injected with saline $(0.5 \mu \mathrm{l} /$ side $)$; the BC 264 group was injected with $0.5 \mu \mathrm{l} /$ side of BC 264 at the doses of 0.01-1 pmol in the dorsal subiculum of the hippocampus, of $1 \mathrm{pmol}$ in the caudate/putamen nucleus, and of $0.1-100 \mathrm{pmol}$ in the prelimbic/infralimbic cortex. Results are expressed as mean \pm SEM of the percentage of time spent in the novel arm. $\star \star p<0.01$ versus control group; Dunnett's test.

arm and explored the three arms equally; L-365,260 impaired performance of rats.

\section{Effects of BC 264 locally injected in the caudate/putamen nucleus of rats in the two-trial memory task after a $\mathbf{6} \mathbf{~ h r}$ intertrial interval}

BC 264 locally injected at the dose of 1 pmol 15 min before the second trial of the memory task did not modify the time spent in the novel arm compared with the control group $(p=0.42)$ (Fig. 3B).

\section{Effects of BC 264 locally injected in the prelimbic/infralimbic cortex of rats in the two-trial memory task after a $\mathbf{6} \mathbf{~ h r}$ intertrial interval}

BC 264 locally injected at the doses of $100 \mathrm{fmol}, 1$ pmol, 10 pmol, or 100 pmol 15 min before the second trial of the memory task did not significantly modify the time spent in the novel arm compared with the control group $\left(F_{(4,39)}=0.432 ; p=0.78\right)$ (Fig. $\left.3 C\right)$.

\section{Microdialysis experiments in the dorsal subiculum/CA1 of the hippocampus of rats}

The mean of the basal extracellular levels of CCK-LIR in control rats was $0.63 \pm 0.03 \mathrm{pg} /$ sample $(n=5)$. There was no significant change in the levels of CCK-LIR according to the time $\left(F_{(9,39)}=\right.$ 0.817; $p=0.604$ ) (Fig. 5A).

Microdialysis technique was performed with rats during the 


\section{A Injection before acquisition phase}

2 hour time interval
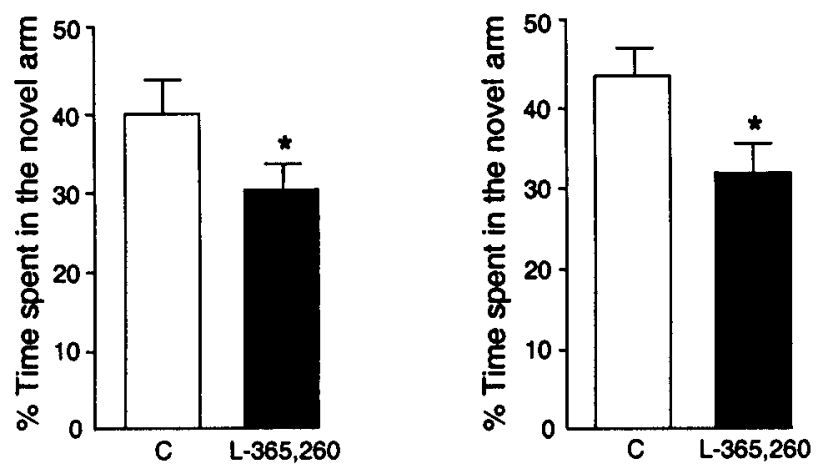

Figure 4. Effects of L-365,260 locally injected into the subiculum dorsal/ CA1 of the hippocampus before the first trial (acquisition phase) $(A)$ and before the second trial (retrieval phase) $(B)$ of the two-trial memory task after a $2 \mathrm{hr}$ time interval. L-365,260 was dissolved in cyclodextrin $(0.5 \%)$. Control rats $(C)$ received $0.5 \mu \mathrm{l} /$ side of cyclodextrin $(0.5 \%)$. The rats were tested $15 \mathrm{~min}$ after L-365,260 or cyclodextrin $(0.5 \%)$ injection. Results are expressed as mean \pm SEM of the percentage of time spent in the novel arm. ${ }^{*} p<0.05$ versus control group; Dunnett's test.

two-trial memory task after a $2 \mathrm{hr}$ intertrial interval. Twelve of 14 rats spent more time in the novel arm during the second trial $(48 \pm 4.2 \%)$. The microdialysis samples of these rats were therefore analyzed. There was a significant time effect in the extracellular levels of CCK-LIR during the two-trial memory task $\left(F_{(12,139)}=2.57 ; p=0.004\right)$ (Fig. 5B). A significant increase in the percentage between the basal levels and the levels obtained during the first trial in the maze was obtained. This increase lasted $1 \mathrm{hr}$, i.e., during the first trial, and $30 \mathrm{~min}$ after this trial (retention phase). Then, the extracellular levels of CCK-LIR returned to the basal values. There is no significant modification of the extracellular levels of CCK-LIR during and after the second trial.

\section{Behavioral experiments with CCK-B receptor-deficient mice}

During the two-trial memory task after a $2 \mathrm{hr}$ intertrial interval, wild-type mice spent more time in the novel arm. In contrast, mutant mice $(n=25)$ significantly spent less time in the novel arm, indicating a decrease of performance $\left(F_{(1,49)}=5.545 ; p=\right.$ $0.02 ; n=26$ ) (Fig. $6 B$ ). There was no modification of the total number of arm visits between the two groups (data not shown).

There was no significant difference between male and female in both behavioral tests

\section{DISCUSSION}

The stimulation of CCK-B receptors by selective CCK-B agonists, such as BC 264 injected by intraperitoneally route, induced an improvement of the performance of both young and old rats in the two-trial memory test, on both the retention and the retrieval phases of the spatial recognition task (Léna et al., 1999; Taghzouti et al., 1999). The aim of this study was to try to characterize the brain structures that are responsible for the improving effects of BC 264 on the retrieval phase in the two-trial memory task and to study the physiological involvement of the CCKergic system in the performance of rodents.

Locally injected into the dorsal subiculum/CA1 of the hip-
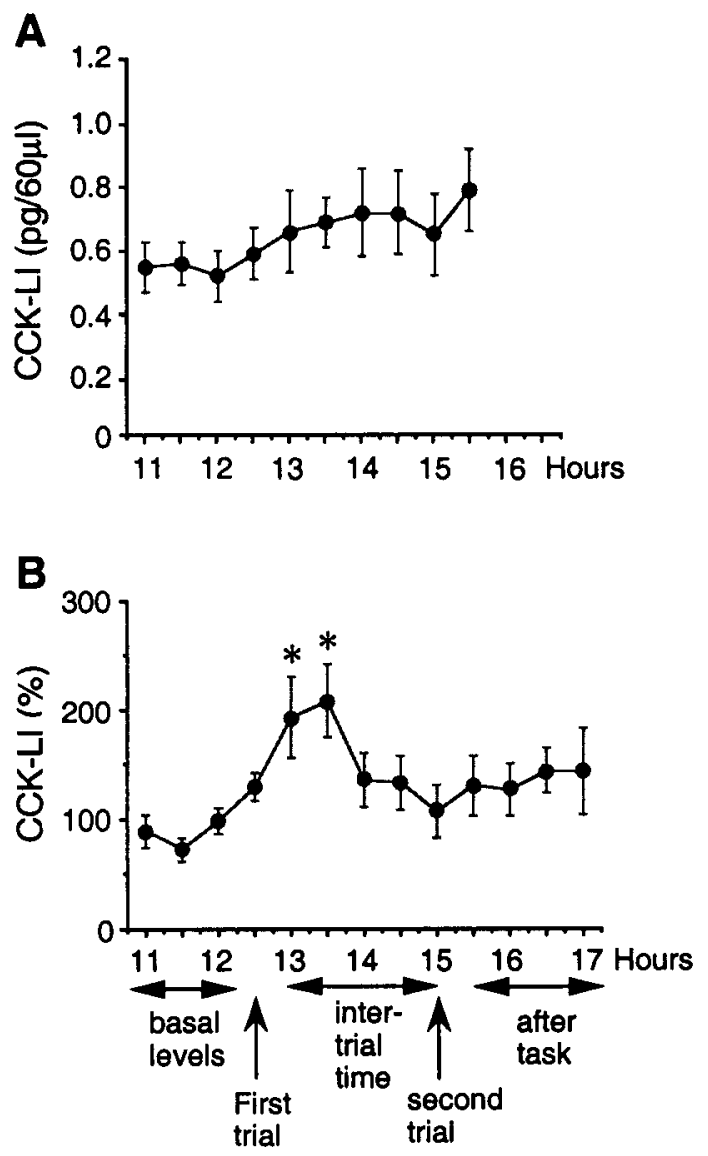

Figure 5. Microdialysis experiments in freely moving rats. $A$, Determination of the extracellular basal levels of CCK-LIR in the subiculum dorsal/CA1 of the hippocampus of rats $(n=5)$. The dialysis samples were collected each $30 \mathrm{~min}$ for $4 \mathrm{hr} 30 \mathrm{~min}$. Results are expressed as mean \pm SEM of CCK-LIR in picograms per sample. There was no significant variation with time. $B$, Determination of the extracellular levels of CCKLIR in the dorsal subiculum of the hippocampus during the two-trial memory task with a $2 \mathrm{hr}$ time interval. Twelve of 14 rats spent more time in the novel arm compared with the 2 familiar ones $(48 \pm 4.2 \%)$. The microdialysis samples of these 12 rats were therefore analyzed. The first four samples were used to calculate the basal levels of CCK-LIR for each rat. Data were then calculated as percentage of the average of the extracellular basal levels before the test. Results are expressed as the mean \pm SEM of the percentage of CCK-LIR in the sample versus basal levels. ${ }^{*} p<0.05$; Dunnett's test.

pocampus in rats, $\mathrm{BC} 264$ reproduced the same responses as those obtained after intraperitoneal injection of the CCK-B agonist. Furthermore, local injection of the selective CCK-B antagonist L-365,260 into the same region of the hippocampus did not produce an effect by itself but completely suppressed the improving effect of BC 264 intraperitoneally injected, showing a participation of this structure in the improvement of performance observed.

In contrast, neither the medial prefrontal cortex nor the caudate/putamen nucleus of rats appeared directly involved in the effects of BC 264, because the agonist did not produce modification of the performance of rats on the retrieval phase, after its local administration in these structures. These results are in agreement with the fact that caudate/putamen nucleus did not seem to mediate spatial memory (Packard et al., 1989; McDonald and White, 1993). On the other hand, they do not exclude a possible indirect participation of the medial prefrontal cortex in BC 264 effects. 


\section{Two-trial spatial recognition task}

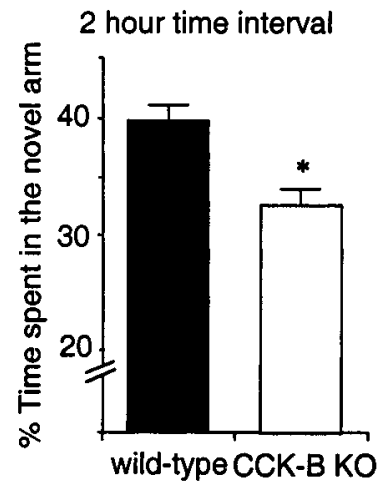

Figure 6. Behavioral experiments with CCK-B receptor-deficient and wild-type mice. Impairment of the performance of CCK-B receptordeficient mice was observed in the two-trial memory task after a $2 \mathrm{hr}$ time interval. Results are expressed as mean \pm SEM of the percentage of time spent in the novel arm. ${ }^{*} p<0.05$ versus wild-type group; Dunnett's test.

The hippocampus is one of the brain structure that contains the highest levels of CCK-LIR and CCK-B receptors (Zarbin et al., 1983; Hill et al., 1987; Pélaprat et al., 1987). In this region, CCK is colocalized with GABA in local circuit neurons (Gulyas et al., 1993). The axons of the CCK-positive neurons were shown to project predominantly to pyramidal neurons in the stratum pyramidale and on the proximal dendrites of these cells in CA1 and CA3 fields (Freund and Buzsàki, 1996). Therefore, the CCKergic system could exert some influence on the outputs from the hippocampus to other brain structures. The N.Acc. could be one of them because the CCKergic interneurons located in the subiculum establish synaptic contacts with glutamatergic neurons projecting to the N.Acc. (Totterdell and Smith, 1986). Several in vitro studies also suggest the existence of interactions between CCKergic and glutamatergic systems in the hippocampus. Thus, $\mathrm{CCK}_{8}$ and selective CCK-B agonists, such as BC 264, increased the firing rate of the hippocampal CA1 neurons (Boden and Hill., 1988; Böhme et al., 1988; Daugé et al., 1990) and produced an increase of basal or $\mathrm{K}^{+}$-evoked-dependent release of aspartate and glutamate from rat hippocampal slices (Migaud et al., 1994; Breukel et al., 1997). In addition, the CCKergic system interacts with the GABAergic system in the hippocampus. Indeed, $\mathrm{CCK}_{8}$ induced GABA release by inhibiting a resting $\mathrm{K}^{+}$conductance in CA1 hippocampal interneurons (Perez de la Mora et al., 1993; Miller et al., 1997). Furthermore, there are arguments that GABAergic interneurons besides glutamate might have an active role in information processing. It was argued that hippocampal GABAergic interneurons have a potential role in providing spatial and temporal conditions for modifications of synaptic weights during hippocampus-dependent memory processes (for review, see Paulsen and Moser, 1998).

On the other hand, BC 264 was also shown, after intraperitoneal administration in rats, to increase the extracellular levels of dopamine in the anterior N.Acc. (Ladurelle et al., 1997). Furthermore, its improving effect in the two-trial memory test was completely suppressed by peripheral injection or local injection in this part of the N.Acc. of the selective D2-like antagonist sulpiride (Ladurelle et al., 1997; I. Léna, H. Dhôtel, C. Garbay, B. P. Roques, and V. Daugé, unpublished observations). However, BC 264 very probably did not directly act in this structure to produce this effect, because local injection of BC 264 in the anterior N.Acc. decreased the dopamine release and produced opposite behavioral responses (Daugé et al., 1992; Ladurelle et al., 1993).

Therefore, one hypothesis to account for the intraperitoneal effects of BC 264 could be that this agonist, acting on the CCK-B receptors located in the dorsal subiculum/CA1 of the hippocampus, stimulates the glutamatergic projections to the anterior N.Acc, resulting in a local increase in dopamine release. However, more complex and indirect pathways could also occur to explain both the action of BC 264 in the hippocampus and the increase of dopamine release obtained in the anterior N.Acc. For example, the increase of dopamine release in the anterior N.Acc. could be generated from the hippocampus, which sends information to the prefrontal cortex, and by a subsequent activation of glutamatergic efferents from the prefrontal cortex to the N.Acc. Accordingly, it was shown that the subiculum-prefrontal cortexN.Acc. network is involved in a spatial memory task (Floresco et al., 1996, 1997). Another possibility could be the involvement of the hippocampus-N.Acc.-dorsomedial thalamus nucleusprefrontal cortex-N.Acc. network (for review, see Gray, 1994). Whatever the case, it was reported that glutamate, locally injected or released after stimulation of cortical or hippocampal afferents, increased the release of DA in the N.Acc. (Imperato et al., 1990; Taber and Fibiger, 1995). Furthermore, the performance of rat in a spatial memory task was abolished after lesion of the hippocampus and was dependent on a concomitant activation of DA transmission in the N.Acc. (Burns et al., 1993; Floresco et al., 1996, 1997).

In the second part of this work, the physiological role of the CCKergic system in the two-trial memory test was analyzed with a $2 \mathrm{hr}$ intertrial interval in which the rats recognized and spent more time in the novel arm than in the two others. In a first experiment, stable basal extracellular levels of CCK-LIR were detected in the dorsal subiculum/CA1 of the hippocampus of control rats. Interestingly, an increase of the extracellular levels of CCK-LIR was observed during the first exposure of the rats to the task (30 min) and during the $30 \mathrm{~min}$ period after this first trial that corresponds to the retention period. Then, the extracellular levels of CCK-LIR slightly decreased to the basal values before the second trial. During and after the second trial, there is a slight increase of released CCK-LIR, but it was not statistically significant. During microdialysis experiments, the animals recognized the novel arm because the number and the duration of visits of the novel arm were significantly higher than those of the other familiar arms, showing that the microdialysis technique did not perturb these behavioral responses. The fact that BC $264 \mathrm{im}-$ proved the performance of rats during the retrieval phase of the task after its injection in the dorsal subiculum/CA1 of the hippocampus and that there was not a significant increase of CCKLIR during this phase could mean that the effect of BC 264 does not correspond to a physiological response. However, the lack of significant increase of the extracellular levels of CCK-LIR during the retrieval phase could be attributable to the too low sensitivity of the technique (the samples corresponded to a $30 \mathrm{~min}$ period of collected dialysate to detecte a basal level of CCK-LIR). To elucidate this point, we performed experiments with the CCK-B antagonist L-365,260. Indeed, its local administration in the dorsal subiculum/CA1 of the hippocampus, before the first trial or before the second trial, completely suppressed the preferential visit of the novel arm in the $2 \mathrm{hr}$ intertrial interval protocol, indicating that a phasic release of CCK very likely occurred during these both phases of the task. This does not seem to be the 
case in the $6 \mathrm{hr}$ intertrial interval protocol, because L-365,260 had no effect by itself when the control rats did not recognize the novel arm (6 hr time interval).

Together, these results are in favor of a physiological participation of the CCKergic system of the dorsal subiculum/CA1 of the hippocampus in this spatial recognition memory task.

Finally, the CCK-B receptor-deficient mice represent an interesting model to investigate the physiological significance of the receptor in vivo. In this study, the impairment of the performance in the two-trial memory task of deficient mice compared with the wild type clearly showed a critical role of CCK-B receptors in this memory process.

In conclusion, these data showed the involvement of the hippocampus in the improving effect of BC 264 on memory processes in rats, emphasized the role of the dorsal subiculum/CA1 in spatial recognition memory, and support a physiological role of the CCKergic system by the interaction of CCK on its CCK-B receptors in spatial memory.

\section{REFERENCES}

Boden PR, Hill RG (1988) Effects of cholecystokinin and pentagastrin on rat hippocampal neurons maintained in vitro. Neuropeptides 12:95-103.

Böhme GA, Stutzmann JM, Blanchard JC (1988) Excitatory effects of cholecystokinin in rat hippocampus: pharmacological response compatible with "central-" or B-type CCK receptors. Brain Res 451:309-318.

Breukel AIM, Lopes da Silva F, Ghijsen Wejm (1997) Cholecystokinin (CCK-8) modulates vesicular release of excitatory amino acids in rat hippocampal nerve endings. Neurosci Lett 234:67-70.

Burns LH, Robbins TW, Everitt BJ (1993) Differential effects of excitotoxic lesions of the basolateral amygdala, ventral subiculum and medial prefrontal cortex on responding with conditioned reinforcement and locomotor activity potentiated by intra-accumbens infusions of D-amphetamine. Behav Brain Res 55:167-183.

Charpentier B, Pélaprat D, Durieux C, Dor A, Reibaud M, Blanchard J-C, Roques BP (1988) Enzyme-resistant CCK analogs with high affinities for central receptors. Peptides 9:835-841.

Chang RSL, Lotti VJ (1986) Biochemical and pharmacological characterization of an extremely potent and selective nonpeptide cholecystokinin antagonists. Proc Natl Acad Sci USA 83:4923-4926.

Corringer PJ, Durieux C, Ruiz-Gayo M, Roques BP (1992) Tritium labelling of two highly selective agonists for CCK-B receptors: $\left[{ }^{3} \mathrm{H}\right]$ propionyl-Tyr $\left(\mathrm{SO}_{3} \mathrm{Na}\right)$-gNle-mGly-Trp- $(\mathrm{N}-\mathrm{Me}) \mathrm{Nle}-\mathrm{Asp}-\mathrm{Phe}-\mathrm{NH}_{2}$ $\left(\left[{ }^{3} \mathrm{H}\right] \mathrm{pBC} \quad 264 ; \quad\left[{ }^{3} \mathrm{H}\right]\right.$ propionyl-gammaD.Glu-Tyr $\left(\mathrm{SO}_{3} \mathrm{H}\right)$-Nle-D.LysTrp-Nle-Asp-Phe- $\mathrm{NH}_{2}$ ([ $\left.\left.{ }^{3} \mathrm{H}\right] \mathrm{pBC} 254\right)$. J Lab Comp Radiopharm 31:459-468.

Daugé V, Böhme GA, Crawley JN, Durieux C, Stutzmann JM, Féger J, Blanchard JC, Roques BP (1990) Investigation of behavioral and electrophysiological responses induced by selective stimulation of CCK-B receptors by using a new highly potent CCK analog, BC 264. Synapse 6:73-80.

Daugé V, Derrien M, Blanchard JC, Roques BP (1992) The selective CCK-B agonist, BC 264 injected in the antero-lateral part of the nucleus accumbens, reduces the spontaneous alternation behaviour of rats. Neuropharmacology 31:67-75.

Daugé V, Mauborgne A, Cesselin F, Fournié-Zaluski M-C, Roques BP (1996) The dual peptidase inhibitor RB101 induces a long-lasting increase in the extracellular level of Met-enkephalin-like material in the nucleus accumbens of freely moving rats. J Neurochem 67:1301-1308.

Daugé V, Léna I (1998) CCK in anxiety and cognitive processes. Neurosci Biobehav Rev 22:815-825.

Daugé V, Samir A, Cupo A, Roques BP (1999) Peripheral stimulation of CCK-B receptors by BC 264 induces a hyperexploration, dependent on the $\partial$ opioid system in the nucleus accumbens of rat. Neuropharmacology, in press.

Dellu F, Mayo W, Cherkaoui J, LeMoal L, Simon H (1992) A two-trial memory task with automated recording study in young and aged rats. Brain Res 588:132-139.

Dellu F, Fauchey V, LeMoal M, Simon H (1997) Extension of a new two trial memory task in the rat: influence of environmental context on recognition processes. Neurobiol Learn Mem 67:112-120.
Floresco SB, Seamans JK, Phillips AG (1996) A selective role for dopamine in the nucleus accumbens of the rat in random foraging but not delayed spatial winshift-based foraging. Behav Brain Res 80:161-168.

Floresco SB, Seamans JK, Phillips AG (1997) Selective roles for hippocampal, prefrontal cortical, and ventral striatal circuits in radial-arm tasks with or without a delay. J Neurosci 17:1880-1890.

Freund AI, Buzsàki G (1996) Interneurons of the hippocampus. Hippocampus 6:347-470.

Gray JA (1994) Modèle général du système limbique et des ganglions de la base: applications à la schizophrénie et aux comportements compulsifs d'allure obsessionnelle. Rev Neurol (Paris) 150:604-613.

Groenewegen HJ, Berendse HW, Meredith GE, Haber SN, Voorn P, Wolters JG, Lohman AHM (1991) Functional anatomy of the ventral, limbic system-innervated striatum. In: The mesolimbic dopamine system: from motivation to action (Willner P, Scheel-Krüger J, eds), pp 19-60. New York: Wiley.

Gulyas AI, Gorcs T, Freund TF (1993) Innervation of different peptidecontaining neurons in the hippocampus by GABAergic septal afferents. Neuroscience 37:31-44.

Hill DR, Campbell NJ, Shaw TM, Woodruff GM (1987) Autoradiographic localization and biochemical characterization of peripheral type CCK receptors in rat CNS using highly selective nonpeptide CCK antagonists. J Neurosci 7:2967-2976.

Imperato A, Honoré T, Jensen LH (1990) Dopamine release in the nucleus caudatus and in the nucleus accumbens is under glutamatergic control through non-NMDA receptors: a study in freely-moving rats. Brain Res 530:223-228.

Itoh S, Lal H (1990) Influences of cholecystokinin and analogues on memory processes. Drug Dev Res 21:257-276.

Katsuura G, Itoh S (1986) Preventive effect of cholecystokinin octapeptide on experimental amnesia in rats. Peptides 7:105-110.

Ladurelle N, Keller G, Roques BP, Daugé V (1993) Effects of CCK8 and of the CCK-B selective agonist BC 264 on extracellular dopamine content in the anterior and posterior nucleus accumbens: a microdialysis study in freely moving rats. Brain Res 628:254-262.

Ladurelle N, Keller G, Blommaert A, Roques BP, Daugé V (1997) The CCK-B agonist, BC 264, increases dopamine in the nucleus accumbens and facilitates motivation and attention after intraperitoneal injection in rats. Eur J Neurosci 9:1804-1814.

Lee YM, Beinborn M, McBride EW, Lu M, Kolakowski Jr LF, Kopin AS (1993) The human brain cholecystokinin-B/gastrin receptor. Cloning and characterization. J Biol Chem 268:8164-8169.

Léna I, Simon H, Roques BP, Daugé V (1999) Opposing effects of two selective CCK-B agonists, on the retrieval phase of a two-trial memory task after systemic injection in the rat. Neuropharmacology 38:543-553.

McDonald RJ, White NM (1993) A triple dissociation of memory systems: Hippocampus, amygdala and dorsal striatum. Behav Neurosci 107:3-22.

Mercer LD, Beart PM (1997) Histochemistry in rat brain and spinal cord with an antibody directed at the cholecystokinin A receptor. Neurosci Lett 225:97-100.

Migaud M, Roques BP, Durieux C (1994) Effects of cholecystokinin octapeptide and BC 264, a potent and selective CCK-B agonist on aspartate and glutamate release from rat hippocampal slices. Neuropharmacology 33:737-743.

Miller K, Hoffer A, Svoboda KR, Lupica CR (1997) Cholecystokinin increases GABA release by inhibiting a resting $\mathrm{K}^{+}$conductance in hippocampal interneurons. J Neurosci 17:4994-5003.

Million ME, Léna I, DaNascimento S, Noble F, Daugé V, Garbay C, Roques BP (1997) Development of new potent agonists able to interact with two postulated subsites of the cholecystokinin CCK-B receptor. Lett Peptide Sci 4:407-410.

Nagata A, Ito M, Iwata N, Kuno J, Takano H, Minowa O, Chihara K, Matsui T, Noda T (1996) G protein-coupled cholecystokinin-B/gastrin receptors are responsible for physiological cell growth of the stomach mucosa in vivo. Med Sci 93:11825-11830.

Packard MG, Hirsh R, White NM (1989) Differential effects of fornix and caudate nucleus lesions on two radial maze: evidence for multiple memory systems. J Neurosci 9:1465-1472.

Paulsen O, Moser E (1998) A model of hippocampal memory encoding and retrieval: GABAergic control of synaptic plasticity. Trends Neurosci 21:273-278.

Paxinos G, Watson C (1986) The rat brain in stereotaxic coordinates, Ed 2. New York: Academic.

Pélaprat D, Broer Y, Studler JM, Peschanski M, Tassin JP, Glowinski J, 
Rostène W, Roques BP (1987) Autoradiography of CCK receptors in the rat brain using $\left[{ }^{3} \mathrm{H}\right] \mathrm{Boc}\left(\mathrm{Nle}_{28,31}\right) \mathrm{CCK}_{27-33}$ and $\left[{ }^{125} \mathrm{I}\right]$ BoltonHunter $\mathrm{CCK}_{8}$; functional significance of subregional distributions. Neurochem Int 10:495-508.

Perez de la Mora M, Hernando-Gomez AM, Menendez-Franco J, Fuxe K (1993) Cholecystokinin-8 increases $\mathrm{K}^{+}$-evoked [ $\left.{ }^{3} \mathrm{H}\right]$ gamaaminobutyric acid release in slices from various brain areas. Eur J Pharmacol 250:423-430.

Robinson TE, Whishaw IQ (1988) Normalization of extracellular dopamine in the striatum following recovery from a partial unilateral 6-OHDA lesion of the substantia nigra: a microdialysis study in freely moving rats. Brain Res 450:209-224.

Taber MT, Fibiger HS (1995) Electrical stimulation of the prefrontal cortex increases dopamine release in the nucleus accumbens of the rat: modulation by metabotropic glutamate receptors. J Neurosci 15:3896-3904.

Taghzouti K, Léna I, Dellu F, Roques BP, Daugé V, Simon H (1999) Cognitive enhancing effects in young and old rats of pBC 264, a selective CCK-B receptor agonist. Psychopharmacology 143:141-149.

Totterdell S, Smith AD (1986) Cholecystokinin-immunoreactive boutons in synaptic contact with hippocampal pyramidal neurons that project to the nucleus accumbens. Neuroscience 19:181-192.

Wank SA, Pisegna JR, De Weerth A (1992) Brain and gastrointestinal cholecystokinin receptor family: structure and functional expression. Proc Natl Acad Sci USA 89:8691-8695.

Zarbin MA, Innis RB, Wamsley JK, Snyder SH, Kuhar MJ (1983) Autoradiographic localization of cholecystokinin receptors in rodent brain. J Neurosci 3:877-906. 